\title{
MANAGEMENT OF CUT THROAT INJURY: A REVIEW OF 20 CASES
}

\author{
Ramesh Parajuli ${ }^{1}$, Tilak Raj Limbu ${ }^{2}$, Ramesh Bhandari ${ }^{1}$, Suman Thapa ${ }^{1}$, Bishow Tulachan ${ }^{3}$
}

\section{ABSTRACT}

INTRODUCTION: Cut throat injury is incised injury or incised resembling injury in the neck usually due to homicidal, suicidal or accidental cause. Multiple vital structures are vulnerable to get injured so it usually requires multi disciplinary approach. The objective of this study is to evaluate cut throat injury in terms of site, severity, cause, motivating factors, age and gender distribution of the victim and the surgical treatment method.

MATERIAL AND METHODS: Retrospective study was carried out by reviewing the chart, from May 2010 to April 2014. Demographics of the patients; cause and motivating factors; site, severity and the type of surgical treatment were recorded and analyzed.

RESULTS: There were a total of 20 patients, of which 14 were males and 6 were females. The most common age group affected was 20-40 years. Homicide was the commonest cause in $12(60 \%)$ patients, followed by suicidal attempt in 6 $(30 \%)$ and accidental injury in $2(10 \%)$ patients. Interpersonal conflict and psychiatric illnesses were the most common motivating factors for the homicidal and suicidal cut throat injury respectively. Most of the patients had zone II injury. Primary repair was the most common surgical treatment method.

CONCLUSION: Young adults are more vulnerable to cut throat injury with majority having zone II injury and homicide being the most common cause. Primary repair is the most common surgical treatment method. Addressing the root cause of violence and identifying and treating the patients with psychiatric illness with suicidal tendency will probably reduce the incidence of cut throat injury in our society.

KEY WORDS: Homicide; Neck injury; Suicide

1. Assistant Professor, Department of ENT, Head and Neck Surgery, Chitwan Medical College \& Teaching Hospital, Chitwan, Nepal

2. Associate Professor, Department of ENT, Head and Neck Surgery, Chitwan Medical College \& Teaching Hospital, Chitwan, Nepal

3. Assistant Professor, Department of ENT, Head and Neck Surgery, Universal College of Medical Sciences \& Teaching Hospital, Bhairahawa, Nepal

\author{
For Correspondence \\ Dr. Ramesh Parajuli \\ Assistant Professor, \\ Department of ENT, Head and Neck Surgery, \\ Chitwan Medical College \& Teaching Hospital, Chitwan, Nepal \\ E-mail:drrameshparajuli@gmail.com
}




\section{INTRODUCTION}

Cut throat injury is an incised injury in the neck that may be superficial or deep; and is usually caused by sharp objects. ${ }^{1}$ Cut throat injury can be a life threatening condition because of the increased risk of injury to the vital structures which are present in such a small confined area. Profuse hemorrhage, shock, air embolism due to injury to the great vessels or asphyxia/airway obstruction resulting from aspirated blood and surrounding tissue edema are the common causes of death following a cut throat injury. It can also result into profound morbidity due to prolonged hospitalization, high cost of health care service, loss of productivity and reduced quality of life. ${ }^{2}$ The cause of cut throat injury may be homicidal, suicidal or accidental. ${ }^{3}$ The motivating factors for homicidal cut throat injury may be land related dispute, robbery, political conflict, familial disharmony, sex related crime etc. Similarly the motivating factors for suicidal attempt usually include psychiatric illness, substance abuse, family problems, poverty, unemployment; and love affair related matters especially in the context of our country. However, the accidental cause of cut throat injury is usually road traffic accidents and fall injuries. ${ }^{3-5}$

Management of the cut throat injury often requires a multi disciplinary approach involving the Otorhinolaryngologist, anesthesiologist, cardiovascular surgeon and psychiatrist. ${ }^{6}$ Airway of the cut throat injury patient is established either via endotracheal intubation or tracheostomy and then surgical repair of the transected tissues; which may need wound debridement if the wound is infected. ${ }^{7}$ While managing the victim with the cut throat injury the aim should be towards restoration of swallowing, phonation and breathing. Cut throat injury patient with the history of suicidal attempt should have a psychiatric consultation to rule out underlying mental illness that may lead to second suicidal attempt by the patient.

The aim of this study is to evaluate cut throat injury in terms of site, severity, cause, motivating factors, age and gender distribution of the victim and surgical treatment method.

\section{MATERIAL AND METHODS}

Retrospective study was carried out in the department of ENT, Head and Neck surgery in a tertiary care hospital in the central Nepal. The study population includes the patients who were brought in the Emergency Room (ER) and subsequently admitted and managed in ENT ward. The study period was of 4 years duration from May 2010 to April 2014. Total 20 cases of cut throat injury were included in the study irrespective of age and sex. Minor injury not requiring admission to the hospital was excluded from the study. The data was obtained from the hospital record books.

Resuscitation of the patient was done in the emergency room according to advanced trauma life support starting with primary survey followed by secondary survey. After stabilizing the vital signs, patients were transferred to operation theatre where debridement and repair of the wound with or without tracheostomy was done depending on the severity of the injury. Blood transfusion with whole blood was carried out in patients who had severe bleeding and those who were brought in the state of shock. The causes of the injury were enquired. Psychiatric evaluation was done in all the patients with the history of suicidal attempt.

Data analysis was done by categorizing the patients according to the demographic pattern, etiology and motivating factors, site (according to defined zones of the neck), and severity of injury and the type of surgical treatment provided.

\section{RESULTS}

During the study period, 20 patients with cut throat injury were brought to this hospital; 14 were males and 6 were females with a male to female ratio of $7: 3$. The age of the patients ranged from 19 to 62 years. However, majority of the patients were young adult male of age group 20 to 40 years. Regarding the etiology of cut throat injury, 12 patients $(60 \%)$ gave history of homicidal attack by known or unknown people, 6 patients $(30 \%)$ had suicidal attempt and the remaining 2 patients $(10 \%)$ were due to accidental cause. While reviewing the history retrospectively the interpersonal conflict $(4 ; 20 \%)$ and psychiatric illness $(3 ; 15 \%)$ were found to be the most common motivating factors for the homicidal and suicidal cut throat injury respectively. Whereas road traffic accident $(1 ; 10 \%)$ and fall from height $(1 ; 10 \%)$ were responsible for accidental cause of cut throat injury. The etiology and motivating factors for the cut throat injury are shown in the table 1.

Table 1: Etiology and motivating factors for the cut throat injury $(\mathbf{n}=\mathbf{2 0})$

\begin{tabular}{llll} 
Cause of injury & Motivating factors & Number & Percentage \\
\hline Homicidal injury & Interpersonal conflict & 4 & $20 \%$ \\
& Land dispute & 2 & $10 \%$ \\
& Family problems & 2 & $10 \%$ \\
& Political conflict & 2 & $10 \%$ \\
& Robbery & 1 & $5 \%$ \\
& Sexual violence & 1 & $5 \%$ \\
Suicidal injury & Total & $\mathbf{1 2}$ & $\mathbf{6 0 \%}$ \\
& Psychiatric illness & 3 & $15 \%$ \\
& Substance abuse & 2 & $10 \%$ \\
& Unemployment & 1 & $5 \%$ \\
& Total & $\mathbf{6}$ & $\mathbf{3 0 \%}$ \\
& & & \\
Accidental injury & Road traffic accident & 1 & $5 \%$ \\
& Fall from height & 1 & $5 \%$ \\
& Total & $\mathbf{2}$ & $\mathbf{1 0} \%$
\end{tabular}


Majority of the patients $(12 ; 60 \%)$ had injury in zone II while 5 patients $(25 \%)$ in zone I; and 3 patients $(15 \%)$ had zone III neck injury. The severity of the injury sustained by our patients is displayed in the table 2 .

\section{Table 2: Severity of the cut throat injury}

$\begin{array}{lcl}\text { Structures injured } & \text { Number } & \text { Percentage } \\ \text { Skin,soft tissue and platysma } & 20 & 100 \% \\ \text { Larynx } & 10 & 50 \% \\ \text { Hypopharynx } & 7 & 35 \% \\ \text { Trachea } & 5 & 25 \% \\ \text { Thyroid gland and vessels } & 3 & 15 \%\end{array}$

Various surgical treatment methods provided to the patients is depicted in the table 3 .

\section{Table 3: Surgical treatment methods}

$\begin{array}{lll}\text { Types of surgical treatment } & \text { Number } & \text { Percentage } \\ \text { Wound debridement and repair } & 18 & 90 \% \\ \text { Tracheostomy } & 14 & 70 \% \\ \text { Laryngeal/hypopharyngeal repair } & 13 & 65 \% \\ \text { Simple repair } & 6 & 30 \%\end{array}$

Primary repair of the wound and tracheostomy were the most common surgical procedures performed accounting for $90 \%$ and $70 \%$ respectively. Beside surgical repair and reconstruction of the wound, 2 of the patients also received blood transfusion because they were brought in the state of hypovolemic shock due to acute blood loss.

\section{DISCUSSION}

Cut throat or penetrating injuries of the neck accounts for 5$10 \%$ of all trauma cases; and is potentially dangerous and requires emergency treatment. ${ }^{8}$ Although less commonly reported in the literature this type of injury can result in morbidity and mortality of the victims which shouldn't be overlooked. Cut throat injury can be acute life threatening or it may lead to morbidities from various complications which depend on the structures injured such as injury to larynx and trachea can result into airway obstruction immediately or laryngotracheal stenosis in due course of time. Similarly, vascular injury can cause hemorrhage, air embolism and cerebral ischemia or stroke. Injury to pharynx and esophagus may result into abscess formation, mediastinitis, and fistula formation such as pharyngocutaneous and esophagocutaneous fistula; septicemia and death. Neurologic injury can result into hoarseness and stridor.
In our study there were total of 20 patients admitted from the emergency department. Of these 20 patients, 14 were male and 6 were female with the male to female ratio being 7:3. Majority of our patients were young male patients $(12 ; 60 \%)$ between 20 and 40 years of age. Our result is similar to the study by Bhattacharya et al. ${ }^{5}$ Male preponderance in this age group is probably due to their involvement in interpersonal violence.

Regarding the causes of cut throat injury, the majority of the patients in this study were due to homicidal injury and the remaining patients were due to suicidal attempt and accidental (unintentional) injury. Interpersonal conflict was the most common motivating/triggering factor for homicidal injury whereas psychiatric illness was the most common motivating factor for the suicidal attempt. Road traffic accident was the responsible for the accidental cause of penetrating neck injury. Similar findings were found in study done by Gilyoma et al.

Photographs of the patients with cut throat injuries are shown in the figure 1 and 2.

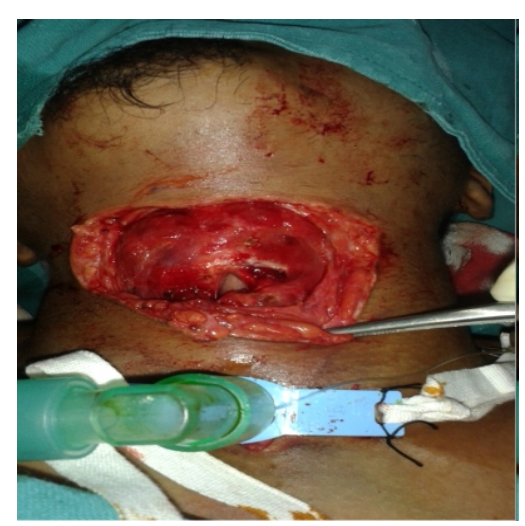

Figure 1: Suicidal cut throat injury

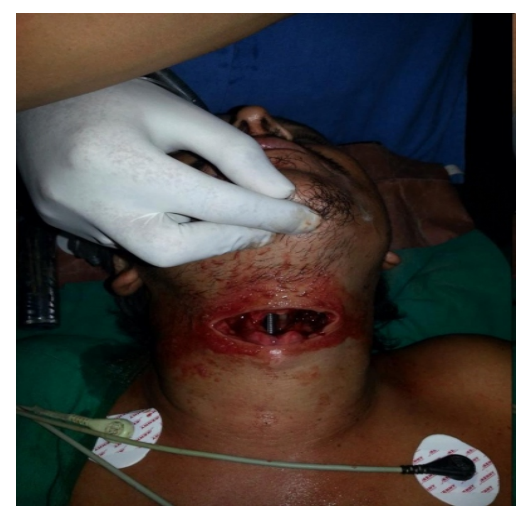

Figure 2 : Homicidal cut throat injury 
Roon and Christensen's classification used for description of the site of neck injury divides neck into three anatomical zones. Zone I is demarcated by the thoracic inlet inferiorly and the cricoid cartilage superioly. Structures at risk in this zone are great vessles like subclavian vessels, brachiocephalic veins, common carotid arteries, aortic arch, jugular veins, trachea, esophagus, lung apices, cervical spine, spinal cord and cervical nerve roots. Zone II encompasses the region from the cricoid cartilage to the angle of the mandible. Important structures in this region include the carotid and vertebral arteries, jugular veins, esophagus, trachea, larynx and spinal cord. Zone III is bounded by the angle of the mandible and the base of the skull. Structures such as salivary glands, carotid and vertebral arteries, jugular veins, cranial nerves (IX-XII) traverse this zone.

Regarding the site of injury, majority of our patients had injury in zone II i.e. in the region between the cricoid cartilage and the angle of mandible as it is usually the most frequently involved (60-75\%) site in penetrating neck injuries. ${ }^{8}$ The reason behind the injury to the zone II more commonly than zone I and III is probably explained by the fact that this region is not protected by bony structures thus making it more vulnerable to the injuries. Most of those patients had injury to the larynx and hypopharynx. Similar pattern of injuries were recorded in various other studies.

In our study the most commonly performed surgical procedures were primary repair of the wound, tracheostomy and laryngeal/hypopharyngeal repair. Patients with injury to the hypopharynx, larynx and trachea underwent tracheotomy to protect airway. Similar results were reported by other authors. ${ }^{5,9}$ There was no any mortality in our study.

Limitation of this study includes its retrospective nature as it doesn't address the follow up issue of the patient which would have been useful to understand the frequency of complications, challenge in the management of complications and their impact on patient's life.

\section{CONCLUSION}

Cut throat injury is not an uncommon problem among young people in our society, the cause of which may be intentional i.e. homicidal or suicidal attempt; or unintentional. Lives of such victims can be saved by efficient emergency health care service and effective transport system.

Majority of patients with cut throat injury require tracheotomy. Addressing the root cause of violence such as poverty, unemployment and substance abuse; and screening and treating the patients with psychiatric illness who have suicidal tendency might be useful in reducing the incidence of cut throat injury in our society.

\section{REFERENCES}

1. Duncan JAT. A case of severely cut throat. Br J Anaesth 1975; 47: 1327-1329.

http://dx.doi.org/10.1093/bja/47.12.1327 PMid:1218174

2. Krug EG, Sharma GK, Lozano R.The global burden of injuries. Am J Publ Health 2000, 90:523526. http://dx.doi.org/10.2105/AJPH.90.4.523 PMid:10754963 PMCid:PMC1446200

3. Manilal A, Khorshed ABM, Talukder DC, Sarder RMA, Fakir AT, Hossain M. Cut throat injury: review of 67 cases. Bangladesh JOtorhinolaryngol 2011;17:513.

4. Onotai LO, Ibekwe U. The pattern of cut throat injuries in the University of Port-Harcourt Teaching Hospital, Portharcourt. Niger JMed 2010, 19(3):264266. http://dx.doi.org/10.4314/njm.v19i3.60178 PMid:20845627

5. Bhattacharjee N, Arefin SM, Mazumder SM, Khan MK: Cut throat injury: a retrospective study of 26 cases. Bangladesh Med Res Counc Bull 1997;23:8790. PMid:9621478

6. Herzog M, Hoppe F, Baier G, Dieler R. Injuries of the head and neck in suicidal intention. Laryngorhinootologie 2005, 84(3):176-81.http://dx.doi.org/10.1055/s-2004-825873 PMid:15770565

7. Ezeanolue B.Management of the upper airway in severe cut throat injuries. Afr JMed Med Sci 2001, 30(3):233 5.PMid: 14510136

8. Darlong LM, Shunyu NB, Das R, Mallik S. Cut throat zone II neck injury and advantage of a feeding jejunostomy. J Emerg Trauma Shock 2009,2(3):213-5

http://dx.doi.org/10.4103/0974-2700.55353 PMid:20009317 PMCid:PMC2776375

9. Gilyoma JM, Hauli KA, Chalya PL. Cut throat injuries at a university teaching hospital in northwestern Tanzania: a review of 98 cases. BMC Emergency Medicine 2014; 14:1-7. http://dx.doi.org/10.1186/1471-227X-14-1PMid:24423426 PMCid:PMC3893495

10. Fagan JJ, Nicol AJ. Neck Trauma. In: Scott-Brown's Otorhinolaryngology, Head and Neck Surgery, 7th Edition. London: Edward Arnold publisher Ltd; 2008:1766-1776. http://dx.doi.org/10.1201/b15118-155 